\title{
Pathophysiology of microwave-induced traumatic brain injury
}

\author{
YUTAKA IGARASHI $^{1}$, YOKO MATSUDA $^{2}$, AKIRA FUSE $^{1}$, TOSHIYUKI ISHIWATA $^{3}$, \\ ZENYA NAITO $^{3}$ and HIROYUKI YOKOTA ${ }^{1}$
}

\author{
${ }^{1}$ Department of Emergency and Critical Care Medicine, Nippon Medical School, Tokyo 113-8603; ${ }^{2}$ Department of Pathology, \\ Tokyo Metropolitan Geriatric Hospital and Institute of Gerontology, Tokyo 173-0015; ${ }^{3}$ Departments of Pathology and \\ Integrative Oncological Pathology, Nippon Medical School, Tokyo 113-8602, Japan
}

Received February 20, 2015; Accepted April 2, 2015

DOI: $10.3892 /$ br.2015.454

\begin{abstract}
Microwave technology has been widely used in numerous applications; however, excessive microwave exposure causes adverse effects, particularly in the brain. The present study aimed to evaluate the change in the number of neural cells and presence of apoptotic cells in rats for one month after exposure to excessive microwave radiation. The rats were exposed to $3.0 \mathrm{~kW}$ of microwaves for $0.1 \mathrm{sec}$ and were sacrificed after $24 \mathrm{~h}(\mathrm{n}=3)$, or $3(\mathrm{n}=3), 7(\mathrm{n}=3), 14(\mathrm{n}=3)$ or 28 days $(\mathrm{n}=4)$ of exposure. The neural cells were counted in the motor cortex and hippocampus [cornu ammonis 1 (CA1) and CA2] and the percentage of positive cells stained with terminal deoxynucleotidyl transferase-mediated deoxyuridine triphosphate nick-end labeling (TUNEL) were also measured, which detected apoptotic cell death in the choroid plexus in the lateral ventricle, motor cortex and hippocampus. In the CA1, the number of neural cells decreased significantly by day 28 compared with that in the control ( 60.7 vs. $50.6, \mathrm{P}=0.0358)$, but did not decrease before day 28 . There were no significant differences on any day in the CA2 and the motor cortex. The number of cells showed a significant increase on day 7 compared to the control in the choroid plexus $(2.1 \pm 1.1$ vs. $21.8 \pm 19.1 \%, \mathrm{P}=0.0318)$. There were no significant differences from the controls in the percentage of TUNEL-positive cells in the motor cortex and hippocampus. The effects of microwave exposure on the brain remain unclear; however, microwave-induced neurotrauma shows the same pathological changes as blast traumatic brain injury.
\end{abstract}

\section{Introduction}

Microwave technology has been widely used in numerous applications, such as food sterilization, mobile communication and heat therapy in medicine (1). Microwaves cause heating within a material by exciting molecules to rotate. This rotation

Correspondence to: Dr Yutaka Igarashi, Department of Emergency and Critical Care Medicine, Nippon Medical School, 1-1-5 Sendagi, Tokyo 113-8603, Japan

E-mail: igarashiy@nms.ac.jp

Key words: microwave, traumatic brain injury, blast injury, animal model, rat produces energy in the form of heat. However, microwaves have a harmful influence on the body.

Cataracts and testis disorders are well-known as adverse effects of microwave (2-5); additionally, microwaves can penetrate the cranium and reach the deep brain. Certain studies have shown that microwaves in the frequency range between 800 and $1,000 \mathrm{MHz}$ can penetrate the cranium and that $<40 \%$ of these can reach the deep brain $(6,7)$ where they may penetrate $<4-5 \mathrm{~cm}$ into the brain $(8,9)$.

Numerous studies have investigated the pathological, biochemical and behavioral changes of the central nervous system resulting from microwave exposure from mobile phones (10-14). The adverse effects of microwave exposure from the Global System for Mobile Communication were studied in an animal model, using $900-\mathrm{MHz}$ radiation at an intensity (such as $0.9 \mathrm{~W} / \mathrm{kg}$ ) and time similar to those of mobile phone emissions (15). These studies focused on chronic changes.

Excessive microwave exposure has been reported to cause trauma and fatal accidents in the early 1970s (16) and change blood-brain barrier permeability $(17,18)$. The higher the microwave output, the larger the blood-brain barrier permeability (19). Although certain studies reported that these changes were caused by high temperature, blood-brain barrier permeability was reported to change in the absence of elevated temperature $(20,21)$. Pathological changes of neural cells induced by microwave exposure have not been well-characterized.

The present study aimed to evaluate the change in the number of neural cells and presence of apoptotic cells in rats for one month following exposure to excessive microwave radiation.

\section{Materials and methods}

Animal model of microwave exposure. A microwave applicator was used to expose rat brains to microwaves to inactivate all enzymes in the brain (Model MMW-05, Muromachi microwave fixation system; Muromachi Kikai Co., Ltd., Tokyo, Japan) (Fig. 1). In animals weighing 300 g, a microwave frequency of $2.45 \mathrm{GHz}$ increased brain temperature to $75-90^{\circ} \mathrm{C}$ at $5.0 \mathrm{~kW}$ for $1.40 \mathrm{sec}$. Microwave output was set between 2 and $5 \mathrm{~kW}$ in $0.01-\mathrm{kW}$ increments and exposure time was set between 0.10 and $2.99 \mathrm{sec}$ in 0.01 -sec increments.

First, to determine the appropriate microwave radiation intensity, 61 male Sprague-Dawley rats (350-400 g; Charles River Laboratories Japan, Inc., Kanagawa, Japan) were used. 
The microwave output resulting in $50 \%$ mortality was determined in preliminary experiments and microwaves at $3.0 \mathrm{~kW}$ for $0.10 \mathrm{sec}$ were used. A total of 31 male Sprague-Dawley rats were used for the following study. The head was positioned prone, fixed on a rat holder and exposed to $3.0 \mathrm{~kW}$ of microwave radiation for $0.1 \mathrm{sec}$ under anesthesia $(360 \mathrm{mg} / \mathrm{kg}$ of chloral hydrate, intraperitoneal injection).

Animals were sacrificed after $24 \mathrm{~h}(\mathrm{n}=3)$, or $3(\mathrm{n}=3), 7(\mathrm{n}=3)$, $14(n=3)$ or 28 days $(n=4)$ of exposure. Animals without microwave exposure were used as controls $(n=3)$. The rats were perfused for fixation with $10 \%$ buffered formalin under anesthesia (360 mg/kg of chloral hydrate, intraperitoneal injection) and their brains were removed and fixed overnight.

All the protocols that involved the use of animals were approved by the Animal Use Committee of Nippon Medical School (approval no. 24-106).

Histological analysis. Fixed brains were cut into 2-mm coronal sections with a brain slicer (Muromachi Kikai Co., Ltd.) and embedded in paraffin using a routine procedure with a vacuum rotary. The paraffin-embedded sections $(3-\mu \mathrm{m})$ were subjected to hematoxylin and eosin (H\&E) staining and the terminal deoxynucleotidyl transferase-mediated deoxyuridine triphosphate nick-end labeling (TUNEL) assay. Although various methods to evaluate brain injury have been reported, we chose to ascertain the extent of neural injury by assessing apoptosis and number of surviving cerebral neurons.

The neural cells were counted in the motor cortex and hippocampus [cornu ammonis 1 (CA1) and CA2]. The percentage of positive cells stained with TUNEL (ApopTag ${ }^{\circledR}$ Peroxidase In Situ Apoptosis Detection kit; Chemicon, EMD Millipore, Billerica, MA, USA) was measured, which detected apoptosis cell death in the choroid plexus in the lateral ventricle, motor cortex and hippocampus (CA1 and CA2). The number of cells differed between sections in the choroid plexus of the lateral ventricle, so the cells were not counted in the choroid plexus. Cells were counted by two investigators and the average was used for analysis.

Statistical analysis. Unless otherwise stated, values are presented as mean \pm standard deviation. Data were analyzed by the Student's t-test. Statistical analyses were performed with StatFlex version. 6.0 (Artech Co., Ltd., Osaka, Japan). $\mathrm{P}<0.05$ was considered to indicate a statistically significant difference.

\section{Results}

Survival rate. Preliminary experiments revealed that $3.2 \mathrm{~kW}$ of microwave radiation for $0.1 \mathrm{sec}$ caused cerebral injury of the cortex after $24 \mathrm{~h}$ of exposure (Fig. 2).

When the radiation intensity was reduced to $3.0 \mathrm{~kW}, 6$ of the 31 rats $(19.4 \%)$ died within $24 \mathrm{~h}$ of microwave exposure and in total, 15 rats (48.4\%) died by day 28 . Rats were exposed to microwave radiation under these conditions and were examined histologically.

Body weight changes. Body weight prior to microwave exposure was $384 \pm 11 \mathrm{~g}$. The body weight significantly decreased to $363 \pm 14 \mathrm{~g}(\mathrm{P}=0.007)$ on day 1 after microwave exposure and $342 \pm 2 \mathrm{~g}(\mathrm{P}<0.001)$ on day 3 , but significantly increased to

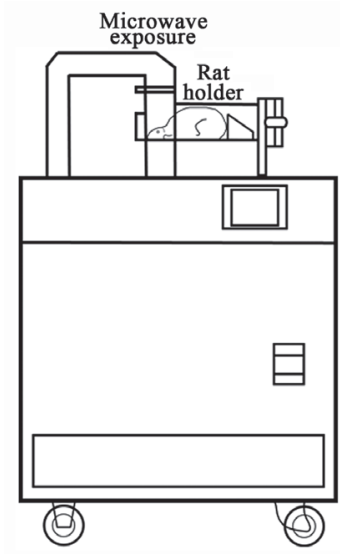

Figure 1. A microwave applicatior. This was used to expose the rat brains to microwaves to inactivate all the enzymes in the brain. The head was positioned prone, fixed on a rat holder in a microwave applicatior and exposed to microwaves.
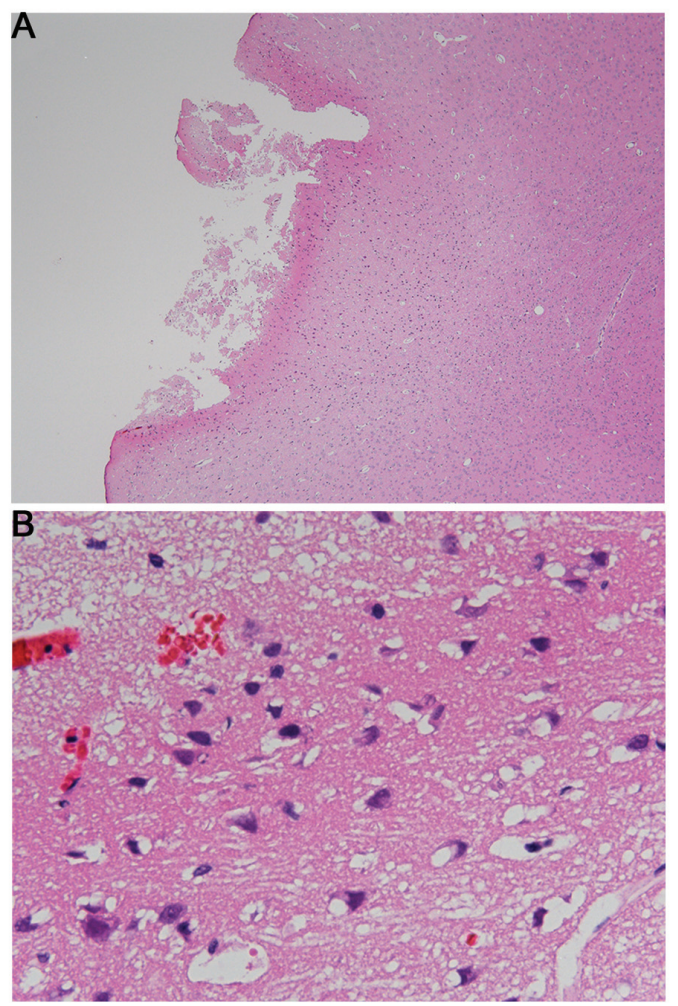

Figure 2. Pathophysiological changes following high-power microwave exposure $(3.2 \mathrm{~kW})$. (A) Necrotic cells in the cerebral cortex [hematoxylin and eosin (H\&E); magnification, $x 40]$. (B) Degeneration and necrosis of neural cells (H\&E; magnification, $\mathrm{x} 600)$.

$402 \pm 10 \mathrm{~g}(\mathrm{P}=0.0151)$ by day 14 . Four rats survived on day 28 , but the body weights of 3 had a deficit and the other weighed $455 \mathrm{~g}$. The body weight increased on day 28 after microwave exposure, but was not statistically significant (Fig. 3).

Pathological changes. H\&E staining showed no cerebral contusion or cerebral edema after exposure to $3.0 \mathrm{~kW}$.

In the CA1, the number of neural cells decreased significantly by day 28 compared with the control (60.7 vs. 50.6, $\mathrm{P}=0.0358$ ), but did not decrease by day 28 . In the CA2 and 


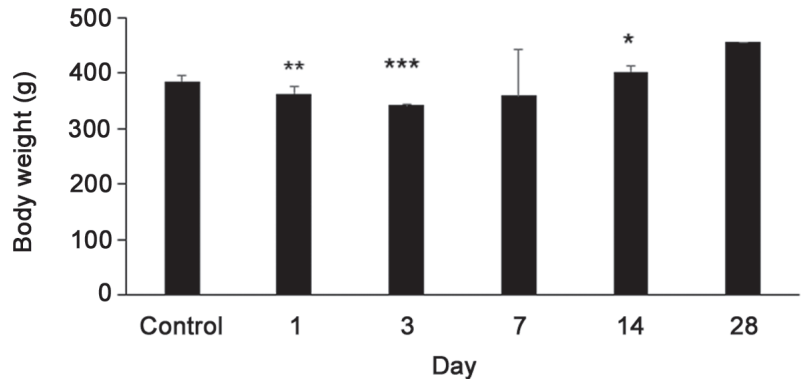

Figure 3. Body weight changes prior and subsequent to microwave exposure The body weight significantly decreased on day $1\left({ }^{* *} \mathrm{P}=0.007\right)$ and day 3 $\left({ }^{* * *} \mathrm{P}<0.001\right)$, but significantly increased on day $14\left({ }^{*} \mathrm{P}=0.0151\right)$.

motor cortex, the number of neural cells did not differ significantly from that in the control (Fig. 4).

In the choroid plexus of the lateral ventricle, the percentage of TUNEL-positive cells was $2.1 \pm 1.1 \%$ in the control group, $4.2 \pm 3.7 \%(\mathrm{P}=0.2191)$ on day $1,9.2 \pm 7.9 \%(\mathrm{P}=0.0547)$ on day 3 and $21.8 \pm 19.1 \%(\mathrm{P}=0.0318)$ on day 7 . There was a significant increase on day 7 compared with the control. However, the percentage of TUNEL-positive cells was $3.4 \pm 3.3 \%(\mathrm{P}=0.3928)$ on day 14 and $5.1 \pm 3.4 \%(\mathrm{P}=0.0596)$ on day 28 . There were no significant differences from controls in the percentage of TUNEL-positive cells in the motor cortex and hippocampus (Fig. 5).

\section{Discussion}

The present study revealed that neural cells decreased in the CA1 on day 28 and that the percentage of apoptotic cells increased in the choroid plexus of the lateral ventricle on day 7 after microwave exposure of $3.0 \mathrm{~kW}$.

Animal models of traumatic brain injury have included fluid percussion injury (22), controlled cortical impact injury $(23,24)$ and weight-drop impact acceleration injury $(25)$. Microwave exposure of $3.2 \mathrm{~kW}$ caused cerebral contusion in the cortex. Although this level of microwave exposure showed no effect on the body surface, cranium, brain surface or cortex, it caused changes deep in the brain. The microwave-induced neurotrauma model appears to be different from other models of traumatic brain injury.

In CA1, the proportion of the apoptotic cells did not increase on any day. Although the neural cells did not

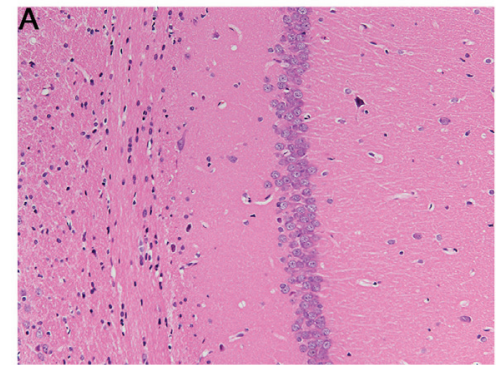

C

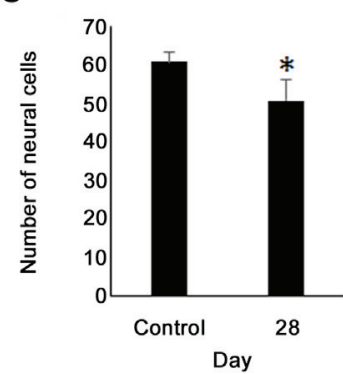

D

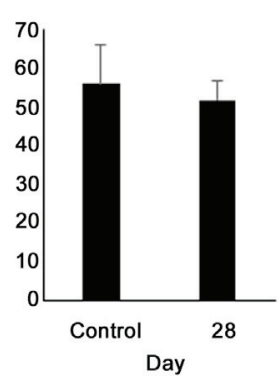

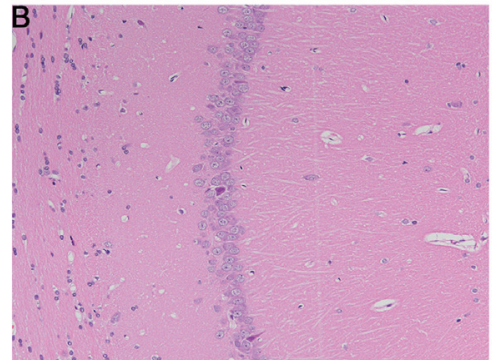

$\mathrm{E}$

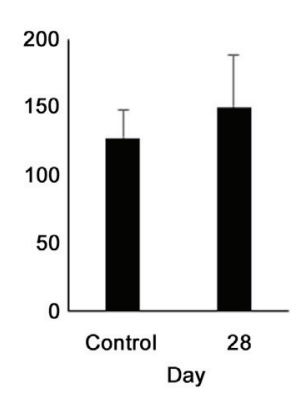

Figure 4. (A) Pathophysiological changes of CA1 between (A) control and (B) day 28 following microwave exposure (hematoxylin and eosin; magnification, $\mathrm{x} 400$ ). Changes in neural cells in the (C) cornu ammonis 1 (CA1), (D) CA2 and (E) morter cortex. ${ }^{*} \mathrm{P}<0.05$.
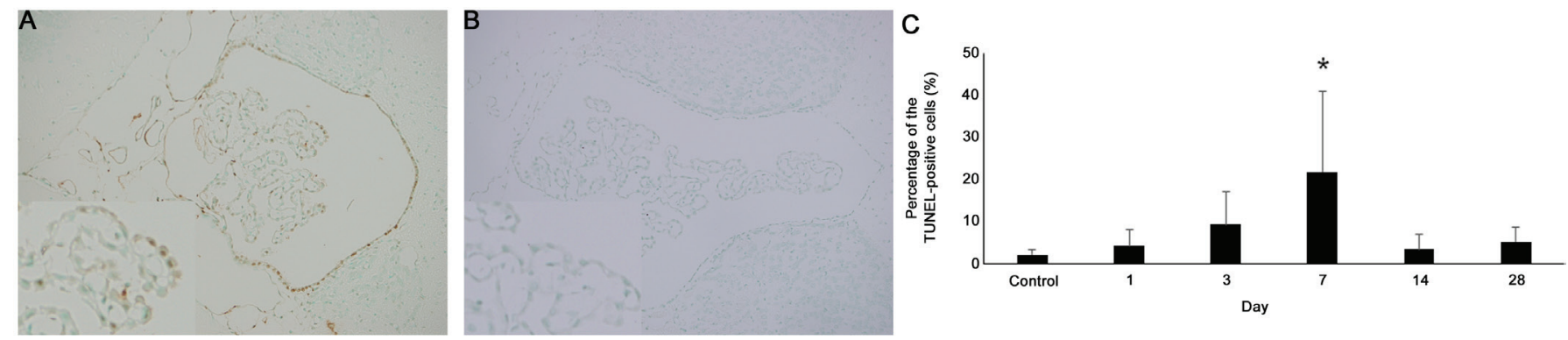

Figure 5. Proportion of the terminal deoxynucleotidyl transferase-mediated deoxyuridine triphosphate nick-end labeling (TUNEL)-positive cells over time in the choroid plexus. (A) Control (TUNEL; magnification, x100). (B) Day 7 (TUNEL; magnification, x100). (C) Changes in the percentage of the TUNEL-positive cells. " $\mathrm{P}<0.05$. 
decrease until day 14, they decreased significantly by day 28 . The central nervous system, particularly the hippocampus, is sensitive to microwave radiation. Previous studies have shown that microwave radiation damaged the hippocampal structure of rats, impaired long-term potentization, reduced neurotransmitter concentration, reduced synaptic vesicles and resulted in memory impairment (26-30). The present study also showed that the neural cells decreased in the hippocampus only, particularly in CA1.

The proportion of apoptotic cells increased by day 7 in the choroid plexus of lateral ventricles for unknown reasons. There was the potential to increase the temperature of the ventricles by microwave excitation of water molecules.

Blast injury is known to cause injury confined to the choroid plexus of lateral ventricles and surrounding tissue (31).

Kaur et al (31) reported that the choroid plexus in rats exhibited ultrastructural changes following an open-field blast and that the intercellular spaces between the choroid plexus epithelial cells were greatly widened, coupled with the massive eruption and possible extrusion of the apical cytoplasm into the ventricular lumen. Garman et al (32) observed blood-brain barrier permeability around the circumventricular organs following the blast using the tube-blast injury model. Thus, microwave-induced neurotrauma and blast injury caused injuries in the choroid plexus of lateral ventricles; however, further studies are required for evaluating damage to axons.

Although the present study showed high mortality, it only showed small pathophysiological changes of the brain and the cause of death was unclear. When comparing survival rate and body weight, survival rate decreased parallel to body weight by day 3 , but survival rate did not continue to decrease after increasing by day 14 . There was no cardiac arrest or respiratory failure immediately following microwave exposure of $3.0 \mathrm{~kW}$.

Microwave-induced neurotraumas are simple and reproducible in animal models of traumatic brain injury. The intensity and time of microwave exposure can be precisely varied.

In conclusion, the present study analyzed the pathological changes in the rat brain following excessive microwave exposure. Apoptotic cells increased in the choroid plexus of the lateral ventricle on day 7 and neural cells decreased in the CA1 by day 28 . The effects of microwave exposure on the brain remain unclear; however, microwave-induced neurotrauma shows the same pathological changes as blast traumatic brain injury.

\section{Acknowledgements}

The present study was supported by Japan Society for the Promotion of Science KAKENHI (grant no. 25462835). The authors would like to thank Mr. Takayuki Asakura for performing the animal experiments.

\section{References}

1. Kesari KK, Kumar S and Behari J: Pathophysiology of microwave radiation: Effect on rat brain. Appl Biochem Biotechnol 166 379-388, 2012.

2. Richardson AW, Duante TD and Hines HM: Experimental cataract produced by $3 \mathrm{~cm}$. Pulsed microwave irradiations. AMA Arch Opthalmol 45: 382-386, 1951.
3. Hirsch FG and Parker JT: Bilateral lenticular opacities occurring in a technician operating a microwave generator. AMA Arch Ind Hyg Occup Med 6: 512-517, 1952.

4. Kalant H: Physiological hazards of microwave radiation: A survey of published literature. Can Med Assoc J 81: 575-582, 1959.

5. Ghanbari M, Mortazavi SB, Khavanin A and Khazaei M: The Effects of Cell Phone Waves (900 MHz-GSM Band) on Sperm Parameters and Total Antioxidant Capacity in Rats. Int J Fertil Steril 7: 21-28, 2013.

6. Kang XK, Li LW, Leong MS and Kooi PS: A method of moments study of SAR inside spheroidal human head and current distribution among handset wireless antennas. J Electromagn Waves Appl 15: 61-75, 2001.

7. Barnett J, Timotijevic L, Shepherd R and Senior V: Public responses to precautionary information from the Department of Health (UK) about possible health risks from mobile phones. Health Policy 82: 240-250, 2007.

8. Dimbylow PJ and Mann SM: SAR calculations in an anatomically realistic model of the head for mobile communication transceivers at $900 \mathrm{MHz}$ and 1.8 GHz. Phys Med Biol 39: 1537-1553, 1994.

9. Rothman KJ, Chou CK, Morgan R, Balzano Q, Guy AW, Funch DP, Preston-Martin S, Mandel J, Steffens R and Carlo G: Assessment of cellular telephone and other radio frequency exposure for epidemiologic research. Epidemiology 7: 291-298, 1996.

10. Hamblin DL, Wood AW, Croft RJ and Stough C: Examining the effects of electromagnetic fields emitted by GSM mobile phones on human event-related potentials and performance during an auditory task. Clin Neurophysiol 115: 171-178, 2004

11. Sievert U, Eggert S and Pau HW: Can mobile phone emissions affect auditory functions of cochlea or brain stem? Otolaryngol Head Neck Surg 132: 451-455, 2005.

12. Ferreri F, Curcio G, Pasqualetti P, De Gennaro L, Fini R and Rossini PM: Mobile phone emissions and human brain excitability. Ann Neurol 60: 188-196, 2006.

13. Krause CM, Pesonen M, Haarala Björnberg C and Hämäläinen $H$ : Effects of pulsed and continuous wave $902 \mathrm{MHz}$ mobile phone exposure on brain oscillatory activity during cognitive processing. Bioelectromagnetics 28: 296-308, 2007.

14. Kumlin T, Iivonen H, Miettinen P, Juvonen A, van Groen T, Puranen L, Pitkäaho R, Juutilainen J and Tanila H: Mobile phone radiation and the developing brain: Behavioral and morphological effects in juvenile rats. Radiat Res 168: 471-479, 2007.

15. Kesari KK, Kumar S and Behari J: 900-MHz microwave radiation promotes oxidation in rat brain. Electromagn Biol Med 30: 219-234, 2011.

16. McLaughlin JT: Tissue destruction and death from microwave radiation (radar). Calif Med 86: 336-339, 1957.

17. Cosquer B, Vasconcelos AP, Fröhlich J and Cassel JC: Blood-brain barrier and electromagnetic fields: Effects of scopolamine methylbromide on working memory after whole-body exposure to $2.45 \mathrm{GHz}$ microwaves in rats. Behav Brain Res 161: 229-237, 2005.

18. Stam R: Electromagnetic fields and the blood-brain barrier. Brain Res Brain Res Rev 65: 80-97, 2010.

19. D'Andrea JA, Chou CK, Johnston SA and Adair ER: Microwave effects on the nervous system. Bioelectromagnetics 24 (Suppl 6): S107-S147, 2003.

20. Salford LG, Brun A, Sturesson K, Eberhardt JL and Persson BR: Permeability of the blood-brain barrier induced by $915 \mathrm{MHz}$ electromagnetic radiation, continuous wave and modulated at 8 , 16, 50 and $200 \mathrm{~Hz}$. Microsc Res Tech 27: 535-542, 1994.

21. Fritze K, Sommer C, Schmitz B, Mies G, Hossmann KA, Kiessling $\mathrm{M}$ and Wiessner C: Effect of global system for mobile communication (GSM) microwave exposure on blood-brain barrier permeability in rat. Acta Neuropathol 94: 465-470, 1997.

22. Dixon CE, Lyeth BG, Povlishock JT, Findling RL, Hamm RJ, Marmarou A, Young HF and Hayes RL: A fluid percussion model of experimental brain injury in the rat. J Neurosurg 67: 110-119, 1987.

23. Lighthall JW: Controlled cortical impact: A new experimental brain injury model. J Neurotrauma 5: 1-15, 1988.

24. Dixon CE, Clifton GL, Lighthall JW, Yaghmai AA and Hayes RL: A controlled cortical impact model of traumatic brain injury in the rat. J Neurosci Methods 39: 253-262, 1991.

25. Marmarou A, Foda MA, van den Brink W, Campbell J, Kita H and Demetriadou K: A new model of diffuse brain injury in rats. Part I: Pathophysiology and biomechanics. J Neurosurg 80: 291-300, 1994. 
26. Xu S, Ning W, Xu Z, Zhou S, Chiang H and Luo J: Chronic exposure to GSM $1800-\mathrm{MHz}$ microwaves reduces excitatory synaptic activity in cultured hippocampal neurons. Neurosci Lett 398: 253-257, 2006.

27. Wang L, Peng R, Hu X, Gao Y, Wang S, Zhao L, Dong J, Su Z, $\mathrm{Xu}$ X, Gao R, et al: Abnormality of synaptic vesicular associated proteins in cerebral cortex and hippocampus after microwave exposure. Synapse 63: 1010-1016, 2009.

28. Zhao L, Peng RY, Wang SM, Wang LF, Gao YB, Dong J, Li X and Su ZT: Relationship between cognition function and hippocampus structure after long-term microwave exposure. Biomed Environ Sci 25: 182-188, 2012

29. Wang H, Peng R, Zhou H, Wang S, Gao Y, Wang L, Yong Z, Zuo H, Zhao L, Dong J, et al: Impairment of long-term potentiation induction is essential for the disruption of spatial memory after microwave exposure. Int J Radiat Biol 89: 1100-1107, 2013.
30. Zhao L, Sun C, Xiong L, Yang Y, Gao Y, Wang L, Zuo H, Xu X, Dong J, Zhou H, et al: MicroRNAs: Novel Mechanism Involved in the Pathogenesis of Microwave Exposure on Rats Hippocampus. J Mol Neurosci 53: 222-230, 2014.

31. Kaur C, Singh J, Lim MK, Ng BL, Yap EP and Ling EA: Studies of the choroid plexus and its associated epiplexus cells in the lateral ventricles of rats following an exposure to a single non-penetrative blast. Arch Histol Cytol 59: 239-248, 1996.

32. Garman RH, Jenkins LW, Switzer RC III, Bauman RA, Tong LC, Swauger PV, Parks SA, Ritzel DV, Dixon CE, Clark RS, et al: Blast exposure in rats with body shielding is characterized primarily by diffuse axonal injury. J Neurotrauma 28: 947-959, 2011. 